\title{
Tumor-associated macrophage, angiogenesis and lymphangiogenesis markers predict prognosis of non-small cell lung cancer patients
}

\author{
Ilseon Hwang 1,7, Jeong Won Kim ${ }^{1,8}$, Kris Ylaya ${ }^{1}$, Eun Joo Chung ${ }^{2}$, Haruhisa Kitano ${ }^{3,5}$, Candice Perry ${ }^{4}$,
} Jun Hanaoka ${ }^{5}$, Junya Fukuoka ${ }^{6}$, Joon-Yong Chung ${ }^{1^{*}}$ (D) and Stephen M. Hewitt ${ }^{\text {* }^{*}}$ (D)

\begin{abstract}
Background: The tumor microenvironment (TME) is a critical player in tumor progression, metastasis and therapy outcomes. Tumor-associated macrophages (TAMs) are a well-recognized core element of the TME and generally characterized as M2-like macrophages. TAMs are believed to contribute to tumor progression, but the mechanism behind this remains unclear. We aimed to investigate the clinical, angiogenic, and lymphangiogenic significance of TAMs in non-small cell lung cancer (NSCLC).
\end{abstract}

Methods: Utilizing combined immunohistochemistry and digital image analysis, we assessed CD68, CD163, VEGF-A, and VEGF-C expression in 349 patients with NSCLC. Subsequently, the potential association between M2 TAMs and angiogenic VEGF-A and/or lymphangiogenic VEGF-C was evaluated for its prognostic value. Furthermore, the effects of M2 TAMs on angiogenesis and lymphangiogenesis were explored via an in vitro co-culture system.

Results: CD68 and CD163 expression were found to directly correlate with VEGF-A and/or VEGF-C expression (all $p<0.001)$. Furthermore, elevated M2 ratio (CD163+/CD68+) was significantly associated with poor overall survival $(p=0.023)$. Dual expression of M2 ratio ${ }^{\text {high }}$ and VEGF-C $C^{\text {high }}$ (M2 ratio ${ }^{\text {high }}$ VEGF-C $C^{\text {high }}$ ) was correlated with worse overall survival $(p=0.033)$. Multivariate analysis revealed that $\mathrm{M} 2$ ratio $^{\text {high }}[\mathrm{HR}(95 \% \mathrm{Cl})=1.53(1.01-2.33), p=0.046]$ and combined M2 ratio ${ }^{\text {high } V E G F-C h i g h ~ e x p r e s s i o n ~[H R ~}(95 \% \mathrm{Cl})=2.01(1.28-3.16), p=0.003$ ] were independent predictors of poor overall survival. Notably, we confirmed that M2 macrophages significantly enhanced the protein and mRNA expression of both VEGF-A and VEGF-C, while M1 macrophages induced only mRNA expression of VEGF-A in A549 cells.

Conclusions: This study suggests that TAMs are significantly associated with angiogenesis and lymphangiogenesis, contributing to the progression of NSCLC. Furthermore, elevated M2 ratio, similar to combined high M2 ratio and high VEGF-C expression, is a strong indicator of poor prognosis in patients with NSCLC, providing insight for future TAMbased immunotherapy strategies.

\footnotetext{
*Correspondence: chungjo@mail.nih.gov; genejock@helix.nih.gov

${ }^{1}$ Experimental Pathology Laboratory, Laboratory of Pathology, Center

for Cancer Research, National Cancer Institute, National Institutes of Health, MSC1500, Bethesda, MD 20892, USA

Full list of author information is available at the end of the article
}

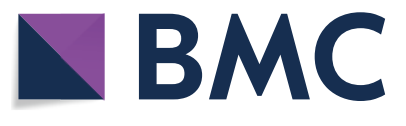

(c) The Author(s) 2020. This article is licensed under a Creative Commons Attribution 4.0 International License, which permits use, sharing, adaptation, distribution and reproduction in any medium or format, as long as you give appropriate credit to the original author(s) and the source, provide a link to the Creative Commons licence, and indicate if changes were made. The images or other third party material in this article are included in the article's Creative Commons licence, unless indicated otherwise in a credit line to the material. If material is not included in the article's Creative Commons licence and your intended use is not permitted by statutory regulation or exceeds the permitted use, you will need to obtain permission directly from the copyright holder. To view a copy of this licence, visit http://creativeco mmons.org/licenses/by/4.0/. The Creative Commons Public Domain Dedication waiver (http://creativecommons.org/publicdomain/ zero/1.0/) applies to the data made available in this article, unless otherwise stated in a credit line to the data. 
Keywords: Tumor-associated macrophage, CD163+/CD68+ ratio, Vascular endothelial growth factor, Angiogenesis, Lymphangiogenesis, Non-small cell lung cancer, Prognosis

\section{Background}

Lung cancer is the primary cause of cancer-related deaths worldwide, and is characterized by a poor prognosis in its advanced stages [1]. Non-small cell lung cancer (NSCLC) accounts for approximately $85 \%$ of reported lung cancer cases with most new NSCLC cases diagnosed at advanced stages [2]. The tumor, node, metastasis (TNM) staging system approved by the International Association for the Study of Lung Cancer (IASLC) and the American Joint Committee on Cancer (AJCC) is used internationally to characterize the extent of disease and its correlations with survival. Thus, current NSCLC treatments are largely guided by TNM stages. Despite the availability of various combined treatments, the overall survival rate of NSCLC patients remains poor, with only $68 \%$ of patients with stage IB and under $10 \%$ of patients with stage IVA-B surviving 5 years post diagnosis. Most deaths during stage III of NSCLC are caused by metastatic recurrence after surgical resection. Furthermore, an estimated $80 \%$ of patients with NSCLC receive an initial diagnosis after their cancer has already spread to regional lymph nodes or metastasized to distant organs [3]. Recently, immune checkpoint inhibitors have been an important component in the management of advanced NSCLC because they have led to improved survival and antitumor response in comparison to that of conventional chemotherapy. Unfortunately, a very limited number of select patients with advanced NSCLC benefitted from such treatment. Currently, programmed death ligand 1 (PDL1) expression on tumor cells $[4,5]$, tumor mutation burden (TMB) [6, 7], tumor-infiltrating lymphocytes (TILs) [8], microsatellite instability (MSI) [9], tumor microenvironment (TME) [10], and microbiome [11] are factors taken under consideration when administering immune checkpoints inhibitors to NSCLC patients. Still, less than $30 \%$ of patients respond to this treatment. Thus, more effective biomarkers are necessary to better predict the effectiveness of immunotherapy and improve risk stratification before treatment.

It is known that leukocytes, including macrophages, infiltrate tumor tissues and form the TME with fibroblasts and vascular endothelial cells. Tumor-associated macrophages (TAMs) are highly plastic and can alter their phenotype (M1 pro-inflammatory or M2 antiinflammatory) according to location and surrounding cytokine milieu in the TME. M1 macrophages are considered to be key players in recognition and destruction of cancer cells [12] whereas M2 macrophages are thought to help promote tumor growth and metastasis in the periphery of solid tumors [13]. CD68 is a pan-macrophage marker, whereas CD163 is a specific marker for the M2 subpopulation [13]. Prior studies have shown that a high density of TAMs is linked to poor patient prognosis in many cancers [14], but other studies have reported contrary results $[15,16]$. Thus, the association between TAMs and cancer prognosis remains controversial.

Angiogenesis and lymphangiogenesis play a critical role in tumor growth and metastasis in NSCLC [17]. Angiogenesis refers to the development and growth of new blood vessels, which support tumor growth, as well as tumor invasion and metastasis, by providing oxygen, nutrients and growth factors. Previous studies have demonstrated that TAMs promote proangiogenic factors in malignant tumors, creating a suitable microenvironment for angiogenesis [18-20]. On the other hand, lymphangiogenesis, the process of forming new lymphatic vessels, is the key initial step in lymphatic and regional lymph node metastasis [21]. The significant association between TAM density and tumor lymphatic vessel density was confirmed in several cancers, including lung cancer [22]. Among the vascular endothelial growth factor (VEGF) family members, VEGF-A and VEGF-C are considered to be major mediators of tumor angiogenesis and lymphangiogenesis, respectively [23]. TAMs are an important driver of angiogenesis and lymphangiogenesis; however, the mechanism of this process remains unclear. Therefore, in this study, we aimed to evaluate stromainfiltrating macrophages (M1 and M2 macrophages), VEGF-A, and VEGF-C expression by immunohistochemistry (IHC) and quantitative digital image analysis. Furthermore, we analyzed the potential association between M2 TAMs and angiogenesis and/or lymphangiogenesis in patients with NSCLC.

\section{Methods \\ Tissue samples}

A total of 349 surgically resected primary NSCLC specimens were collected. This includes samples from South Korean patients $(n=102)$ who underwent curative surgery and adjuvant chemotherapy at Keimyung University Dongsan Medical Center between January 2010 and December 2012, and samples $(n=247)$ from Japanese patients who underwent curative resections between 1993 and 2004 at Toyama University Hospital and National Hospital Organization Higashi-Ohmi General Medical Center, as previously reported [24]. TNM 
classification of NSCLC tumors were staged according to the eighth edition Lung Cancer standards [25], Grading was done according to the 2015 World Health Organization (WHO) guidelines. Clinicopathological characteristics and clinical outcome data were retrospectively collected from medical records and pathology reports. The median follow-up period for the Korean and Japanese cohorts was 42.6 months (range 0.768.5 months) and 28.0 months (range 0-311.0 months), respectively. This study was approved by the Institutional Review Board at Keimyung University Dongsan Medical Center (DSMC 2020-01-020, Daegu, Republic of Korea), Toyama University Hospital (Toyama, Japan), and National Hospital Organization Higashi-Ohmi General Medical Center (Shiga, Japan).

\section{Tissue microarray and immunohistochemistry}

Tissue Microarray (TMA) was constructed from archival formalin-fixed, paraffin-embedded (FFPE) tissue blocks. Three $1.0 \mathrm{~mm}$ diameter tissue cores were arrayed on a recipient paraffin block using a tissue arrayer (Pathology Devices, Westminster, MD), in which a representative tumor area was carefully selected for each tumor from a hematoxylin and eosin (H\&E) stained section of a donor block. TMA blocks were cut into serial $5-\mu \mathrm{m}$-thick sections, heated for $1 \mathrm{~h}$ at $60^{\circ} \mathrm{C}$, deparaffinized in xylene, and rehydrated through a series of graded alcohol to distilled water. Heat mediated antigen retrieval was performed in a pressure chamber (Pascal; Dako, Carpinteria, CA) with pH 6.0 citrate buffer (Dako) for CD68, CD163 and VEGF-C, but pH 9.0 citrate buffer (Dako) for VEGF-A. Endogenous peroxidase activity was quenched using a 3\% solution of aqueous hydrogen peroxide and non-specific binding was blocked with an additional protein block (Dako). Subsequently, primary antibody hybridization was carried out with the following: mouse monoclonal anti-CD68 (Clone Kp1; diluted 1:5000; Dako) for $30 \mathrm{~min}$, rabbit monoclonal anti-CD163 (clone EPR19518, diluted 1:1000; Abcam, Cambridge, MA) for $1 \mathrm{~h}$, mouse monoclonal anti-VEGF-A (clone VG1; diluted 1:100; Thermo Fisher Scientific, Waltham, MA) for $1 \mathrm{~h}$; goat polyclonal anti-VEGF-C (Cat.\# AF752; diluted 1:100; R\&D Systems, Minneapolis) at $4{ }^{\circ} \mathrm{C}$ overnight incubation. Signals were detected with an Envision + detect system (Dako). The stains were visualized using 3,3'-diaminobenzidine (DAB), lightly counterstained with hematoxylin, dehydrated in ethanol, and cleared in xylene. In a similar manner, dual staining of CD68 and CD163 was performed using a CINtec Plus Cytology Kit (CINtec PLUS; Roche, Indianapolis, IN), modified for FFPE tissue-based specimens. Briefly, endogenous activity was blocked with hydrogen peroxidase, followed by an incubation with a primary antibody cocktail, consisting of mouse
anti-CD68 and rabbit anti-CD163, for $1 \mathrm{~h}$ at an aforementioned dilution. Multicolor brown/red enzymatic reactions were detected using a horseradish peroxidase (HRP) and alkaline phosphatase (AP) polymer-based system (CINtec PLUS), then proceeded with DAB and substrate Red chromogen labeling. After rinsing and light hematoxylin counter staining, slides were allowed to air dry, briefly cleared in xylene, and coverslipped. Immunoglobulin G (IgG) isotype and omission of the primary antibodies were used as negative controls. Positive controls were in TMA including testis tissues.

\section{Digital image analysis}

Immunohistochemically stained slides were scanned using an Aperio AT2 digital scanner with a $40 \times$ objective (Leica Biosystems Inc., Buffalo Grove, IL). The images were analyzed using Visiopharm Digital Image Analysis (DIA) software (for Windows 7, version 6.9.1; Visiopharm, Hørsholm, Denmark). The cytoplasm was defined by outlining the nucleus with a system trained to digitally "paint" cell nuclei. The proportion of positively brownstained cells was obtained using a predefined algorithm and optimized settings, as previously described [26]. The immunohistochemical score was expressed as the percentage of positive cells (possible range $0-100$ ). The median values were used as cut-off values for discriminating between low and high expression of immunohistochemical staining. Cut-off values for CD68, CD163, VEGF-A, VEGF-C, and M2 ratio (CD163+/CD68+) were $8.70 \%, 10.12 \%, 7.42 \%, 3.09 \%$, and 1.17 with high cytoplasmic staining, respectively.

\section{Cell culture}

THP-1 and A549 cells were purchased from the ATCC (Manassas, VA) and cultured in RPMI 1640 (Invitrogen, Carlsberg, CA), containing $10 \%$ of heat inactivated fetal bovine serum (Invitrogen), in a $37{ }^{\circ} \mathrm{C} \mathrm{CO}_{2}$ incubator. The culture medium for THP-1 cells was supplemented with $0.05 \mathrm{mM} \beta$-mercaptoethanol (Gibco, 31350-010; Thermo Fisher Scientific). For differentiation of monocytic THP-1 cells towards macrophage (M0) phenotype, cells were incubated with $150 \mathrm{nM}$ phorbol 12-myristate 13-acetate (PMA, P8139; Millipore Sigma, Burlington, MA) for $24 \mathrm{~h}$. Differentiated macrophages were polarized toward M1 or M2 macrophages.

\section{Co-culture with A549 cells and polarized macrophages}

For co-culture experiments with A549 cells and polarized macrophages, differentiated M0 macrophages from THP-1 were transferred into a 12-transwell insert $\left(2 \times 10^{5}\right.$ cells /insert, membrane pore size of $0.4 \mu \mathrm{m}$, Corning, \#3450) and treated with $10 \mathrm{pg} / \mathrm{ml}$ of lipopolysaccharide (LPS; Sigma, \#8630), or $20 \mathrm{ng} / \mathrm{ml}$ of interleukin 4 (R\&D 
Systems, \#204-IL) and $20 \mathrm{ng} / \mathrm{ml}$ of interleukin 13 (R\&D Systems, \#213-ILB), for $72 \mathrm{~h}$. A549 cells were seeded into a new 12-well plate $\left(2 \times 10^{4}\right.$ cells/well $)$ and incubated in RPMI containing 10\% FBS, $24 \mathrm{~h}$ prior to co-culture. Polarized macrophages were washed with PBS three times in transwell inserts and co-cultured with A549 cells already plated in a new 12-well plate. After $48 \mathrm{~h}$, only cells were collected for further experiments such as quantitative real-time polymerase chain reaction (PCR) or enzyme-linked immunosorbent assay (ELISA).

\section{ELISA}

Proteins were prepared from collected cells, and VEGF-A and VEGF-C protein levels were quantified in cell lysates (100 $\mu \mathrm{g}$ of total protein) by using specific ELISA kits (R\&D system, Minneapolis, MN) according to the manufacturer's instruction.

\section{Quantitative real-time PCR}

To assess VEGF- $A$ and $V E G F-C$ mRNA levels, total RNA was extracted from macrophages, derived from THP-1 cells, and A549 cells using a Qiagen RNeasy Mini kit (Qiagen, Valencia, CA), then converted to cDNA using a QuantiTech Reverse Transcriptase kit (Qiagen) according to the manufacturer's protocols. Quantitative realtime PCR was performed with $0.5 \mu \mathrm{g}$ of cDNA assayed in a $50 \mu \mathrm{L}$ reaction volume. The reactions were incubated for $2 \mathrm{~min}$ at $50{ }^{\circ} \mathrm{C}, 10 \mathrm{~min}$ at $95^{\circ} \mathrm{C}$ for initial denaturing, then run through 40 cycles of $95^{\circ} \mathrm{C}$ for $15 \mathrm{~s}$ and $60^{\circ} \mathrm{C}$ for 1 min in 7500 Taqman assays from ABI (Applied Biosystems, Foster City, CA).

\section{Statistical analysis}

Statistical analyses were performed using R 3.5.2 ( R Development Core Team, Vienna, Austria, https:// www.R-project.org) and the SPSS Statistics for Windows, version 23 (IBM Corp., Armonk, NY). Differences in clinicopathological features between low and high expression of CD68, CD163, VEGF-A and VEGF-C were analyzed using Chi-square or Fisher's exact test for categorical variables and the Student's $t$ test for continuous variables. Survival rate was determined by the Kaplan-Meier method, and the log-rank test was used to compare survival rates among subgroups. The log-rank test was used for univariate analysis and independent prognostic factors were identified by multivariate analysis, using the Cox proportional hazards model to calculate hazard ratios.

At first, pathologic $\mathrm{T}$ stage, $\mathrm{N}$ stage and $\mathrm{M} 2$ ratio $(\mathrm{CD} 163+/ \mathrm{CD} 68+)$ were included as covariates, and then pathologic $\mathrm{T}$ stage, $\mathrm{N}$ stage and $\mathrm{M} 2$ ratio/VEGF$\mathrm{C}$ were included as covariates. The results of the Cox model analysis were reported using hazard ratios and
95\% confidence intervals (CIs). $P$ values of less than 0.05 were defined as indicators of statistically significant differences.

\section{Results}

\section{Clinicopathological characteristics of patients}

The study group was composed of 241 (69.1\%) males and $108(30.9 \%)$ females with a mean age of $65.5 \pm 8.59$ years (range 35 to 90 years). There were 210 (60.2\%) patients with adenocarcinoma, $135(38.7 \%)$ patients with squamous cell carcinoma, and $4(1.1 \%)$ patients with adenosquamous carcinoma. Histologically, 125 (35.8\%) tumors were graded as well-differentiated, $158(45.3 \%)$ as moderately differentiated, and $66(18.9 \%)$ as poorly differentiated. Stage pT1, pT2, pT3, and pT4 tumors were identified in 155 (44.4\%), 148 (42.4\%), 43 (12.3\%), and $3(0.9 \%)$ patients, respectively. Lymph node metastasis occurred in 102 patients (29.2\%); pN stage was pN1 in $52.9 \%(54 / 102)$, pN2 in $45.1 \%(46 / 102)$, and $\mathrm{pN} 3$ in $2.0 \%$ $(2 / 102)$ of patients. Stage I, II, III, and IV lesions at initial diagnosis were present in 218 (62.5\%), 72 (20.6\%), 52 (14.9\%), and $7(2.0 \%)$ patients, respectively. Of the 349 patients, $93(26.6 \%)$ had died at the time of analysis. The overall 5-year survival rate was $45.9 \%$. The clinicopathological characteristics of the patients are summarized in Additional file 1: Table S1.

\section{Expression of TAM, angiogenesis and lymphangiogenesis markers}

CD68 and CD163 positive macrophages were predominantly detected in the tumor stroma and intervening space between tumor cells. We confirmed the location of CD68 and CD163 positive macrophages using CD68 and CD163 dual staining (Fig. 1a-c). Immunohistochemical staining of VEGF-A and VEGF-C identified their presence in tumor cells and mesenchymal cells in the stroma (Fig. 1d, e). A total of 174 (49.9\%) tumors were classified as samples highly expressing CD68 $\left(\mathrm{CD} 68^{\mathrm{High}}\right)$, CD163 $\left(\mathrm{CD} 163^{\text {High }}\right)$, and VEGF-A (VEGF-A ${ }^{\text {High }}$ ), while $175(50.1 \%)$ tumors were determined to highly express VEGF-C (VEGF-C ${ }^{\text {High }}$ ) (Table 1).

Table 1 depicts the correlations among CD68, CD163, M2 ratio (CD163+/CD68+), VEGF-A, VEGF-C, and clinicopathologic features. Male patients frequently had a higher M2 ratio than female patients $(p=0.017)$. CD163 ${ }^{\text {High }}$, VEGF- $A^{\text {High }}$ and VEGF- $C^{\text {High }}$ expression were significantly associated with the histological type of squamous cell carcinoma $(p=0.027, p=0.015$, and $p<0.001$, respectively). $\mathrm{CD} 68^{\mathrm{High}}$ and VEGF- $\mathrm{C}^{\mathrm{High}}$ correlated with less differentiated tumors $(p=0.030$ and $p=0.001$, respectively). There was no association between CD68, 


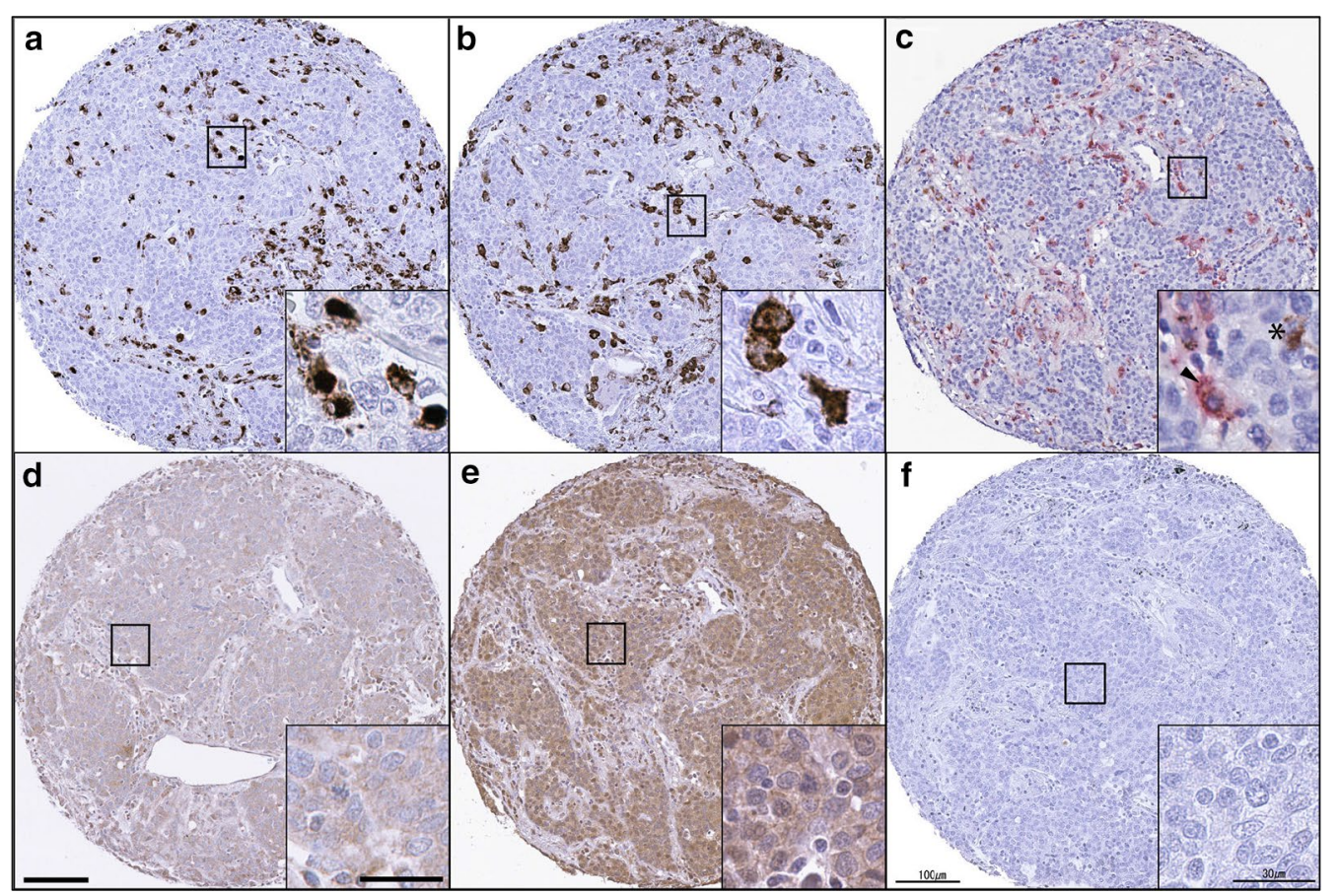

Fig. 1 Tumor-associated macrophage markers (CD68 \& CD163), VEGF-A, and VEGF-C expression in human non-small cell lung cancer (NSCLC) tissues. Representative immunohistochemical images of CD68 (a), CD163 (b), double staining of CD68 and CD163 (c), VEGF-A (d), and VEGF-C (e), immunoglobulin G (lgG) isotype control (f). Arrowhead indicates dual stained CD163 (red) and CD68 (brown), and asterisk indicates CD68. Scale $\operatorname{bar}=100 \mu \mathrm{m}(30 \mu \mathrm{m}$ in inset)

CD163, VEGF-A, and VEGF-C expressions and NSCLC patient's age, pathological $\mathrm{T}$ and $\mathrm{N}$ status, and stage.

Subgroup analysis according to M2 ratio and VEGF-A or VEGF-C expression status (Additional file 1: Tables S2 and S3) revealed that combined M2 ratio ${ }^{\text {High }}$ VEGF- $\mathrm{A}^{\text {High }}$ and combined M2 ratio $^{\text {High }}$ VEGF- $\mathrm{C}^{\text {High }}$ were predominantly found in males $(p=0.022$ and $p<0.001$, respectively). Combined M2 ratio ${ }^{\text {High }}$ VEGF-C ${ }^{\text {High }}$ was linked with squamous cell carcinoma $(p<0.001)$, while combined M2 ratio ${ }^{\text {Low }}$ VEGF-C ${ }^{\text {Low }}$ was linked with well differentiated tumors $(p=0.010)$. In the squamous cell carcinoma subgroup, VEGF-C $C^{\text {High }}$ was associated with less differentiation $(p=0.029)$ (Additional file 1 : Table S4). However, no significant association was observed in the adenocarcinoma group (Additional file 1: Table S5).

\section{Correlation between TAMs and VEGF-A or VEGF-C expression}

CD68 expression showed a significant positive correlation with CD163 (Pearson correlation $r=0.559, p<0.001$, Fig. 2a) and VEGF-A expression (Pearson correlation $r=0.563, p<0.001$ ), while a moderate correlation was observed between CD68 and VEGF-C expression (Pearson correlation $r=0.354, p<0.001$, Fig. 2c). CD163 expression moderately correlated with VEGF-A (Pearson correlation $r=0.411, p<0.001$, Fig. $2 d$ ) and VEGFC (Pearson correlation $r=0.320, p<0.001$, Fig. 2e) as well. There was a strong correlation between VEGF-A and VEGF-C expression (Pearson correlation $r=0.593$, $p<0.001$, Fig. 2f). Furthermore, VEGF-A and VEGF$C$ protein expression directly correlated with elevated CD68 and CD163 expression (Additional file 2: Fig. S1).

In subgroup analyses, CD68 expression was strongly correlated with CD163 (Pearson correlation $r=0.636$, $p<0.001$ ) and VEGF-A (Pearson correlation $r=0.533$, $p<0.001)$ expression, while there was a moderate correlation between CD68 and VEGF-C (Pearson correlation $r=0.329, p<0.001$ ) expression (Additional file 2: Fig. S2) in adenocarcinoma patients. CD163 expression also significantly correlated with VEGF-A expression (Pearson correlation $r=0.459, p<0.001$ ). On the other hand, there was a weak correlation between CD163 and VEGF-C (Pearson correlation $r=0.275, p<0.001$ ) expression (Additional file 2: Fig. S2) in adenocarcinoma cases. Similar correlation coefficient values were observed in squamous cell carcinoma patients (Additional file 2: Fig. S3). There were significant correlations between CD68 and CD163 (Pearson correlation $r=0.473, p<0.001$ ) or VEGF-A (Pearson correlation $r=0.574, p<0.001$ ) 


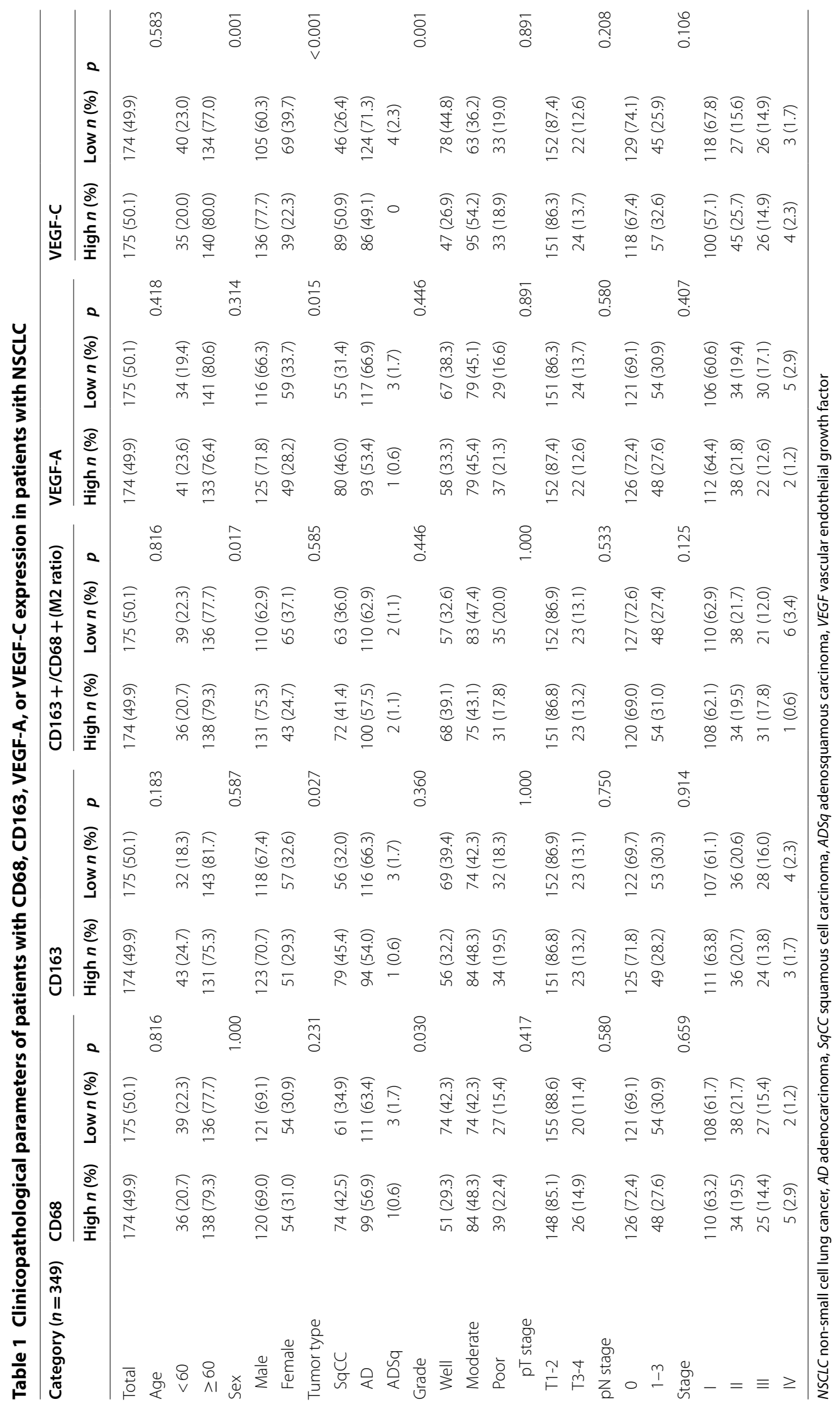



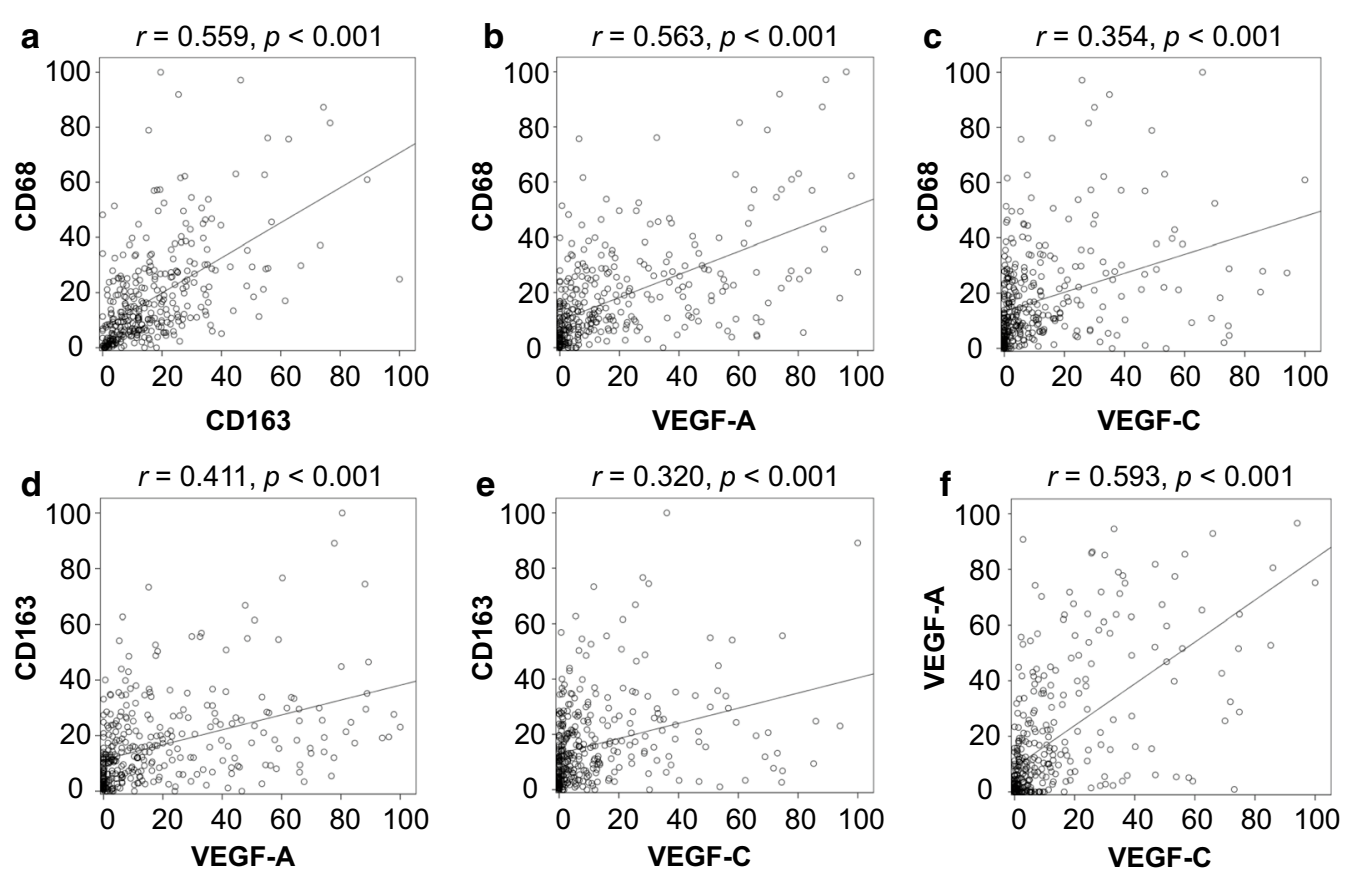

Fig. 2 Correlation among tumor-associated macrophage-, angiogenesis- and lymphangiogenesis-related markers in patients with NSCLC. CD68 expression positively correlated with CD163 (a), VEGF-A (b), and VEGF-C (c) expression. CD163 expression showed a significant positive correlation with VEGF-A (d) and VEGF-C (e) expression. There is a strong positive correlation between VEGF-A and VEGF-C (f)

expression while CD68 expression was moderately correlated with VEGF-C (Pearson correlation $r=0.337$, $p<0.001)$ expression in squamous cell carcinoma. There were also moderate correlations between CD163 and VEGF-A (Pearson correlation $r=0.356, p<0.001$ ) or VEGF-C (Pearson correlation $r=0.325, p<0.001$ ) expression in squamous cell carcinoma. Moreover, there were significant correlations between VEGF-A and VEGF-C in both adenocarcinoma (Pearson correlation $r=0.439$, $p<0.001$ ) and squamous cell carcinoma (Pearson correlation $r=0.574, p<0.001$ ) (Additional file 2: Fig. S2, S3).

\section{Survival analysis of TAMs, VEGF-A, and VEGF-C expression}

We next examined the relationship between TAMs, VEGF-A, and VEGF-C expression and patient survival outcomes in 349 NSCLC patients with available overall survival data. NSCLC patients with high CD68 expression displayed significantly better overall survival (OS) (log-rank $p=0.023)$ than those with low CD68 expression (Fig. 3a). In contrast, a significant OS difference was observed between patients with a high M2 ratio (log-rank $p=0.023)$ and patients with a low M2 ratio (Fig. 3c). In subgroup analyses, adenocarcinoma NSCLC patients with high CD68 expression (log-rank $p=0.034$ ) showed a significant survival advantage (Additional file 2: Fig. S4a), whereas adenocarcinoma NSCLC patients with high M2 ratio (log-rank $p=0.047$ ) had poor survival (Additional file 2: Fig. S4c). However, CD68, CD163, VEGF-A, and VEGF-C expression, as well as M2 ratio, was not found to be associated with patient $O S$ in squamous cell carcinomas (Additional file 2: Fig. S5).

To investigate whether M2 ratio and VEGF family members have a combined effect on NSCLC prognosis, patients were divided into 4 groups according to M2 ratio and VEGF-A expression: M2 ratio ${ }^{\text {low } V E G F-A ~}{ }^{\text {low }}$, M2 ratio ${ }^{\text {low } V E G F-A ~}{ }^{\text {high }}$, M2 ratio ${ }^{\text {high }}$ VEGF-A ${ }^{\text {low }}$, and M2 ratio ${ }^{\text {high }}$ VEGF-A ${ }^{\text {high }}$. In pairwise comparisons, patients with M2 ratio ${ }^{\text {high }}$ VEGF-A ${ }^{\text {high }}$ had significantly worse survival than those with M2 ratio $^{\text {low }}$ VEGF-A ${ }^{\text {high }}$ $(p=0.004)$, while there were no significant survival differences between M2 ratio ${ }^{\text {low } V E G F-A ~}{ }^{\text {low }}(p=0.728)$ and M2 ratio ${ }^{\text {high }}$ VEGF-A ${ }^{\text {low }}(p=0.714)$. Kaplan-Meier plots revealed that patients with M2 ratio $^{\text {high }}$ VEGF-A ${ }^{\text {high }}$ had a tendency of worse overall survival, but this trend was not significant (log-rank $p=0.056$, Fig. 4a). We next analyzed a potential correlation between prognosis and the combination of M2 ratio and VEGF-C expression in patients with NSCLC. In pairwise comparisons, patient survival in the M2 ratio $^{\text {high }}$ VEGF-C ${ }^{\text {high }}$ group was significantly worse than that for the M2 ratio ${ }^{\text {low } V E G F-C ~}{ }^{\text {low }}$ $(\log$-rank $p=0.047)$ and M2 ratio ${ }^{\text {low }}$ VEGF-C $C^{\text {high }}$ (log-rank $p=0.008$ ) groups. However, there was no significant survival difference between M2 ratio ${ }^{\text {high }}$ VEGF-C $C^{\text {high }}$ and M2 

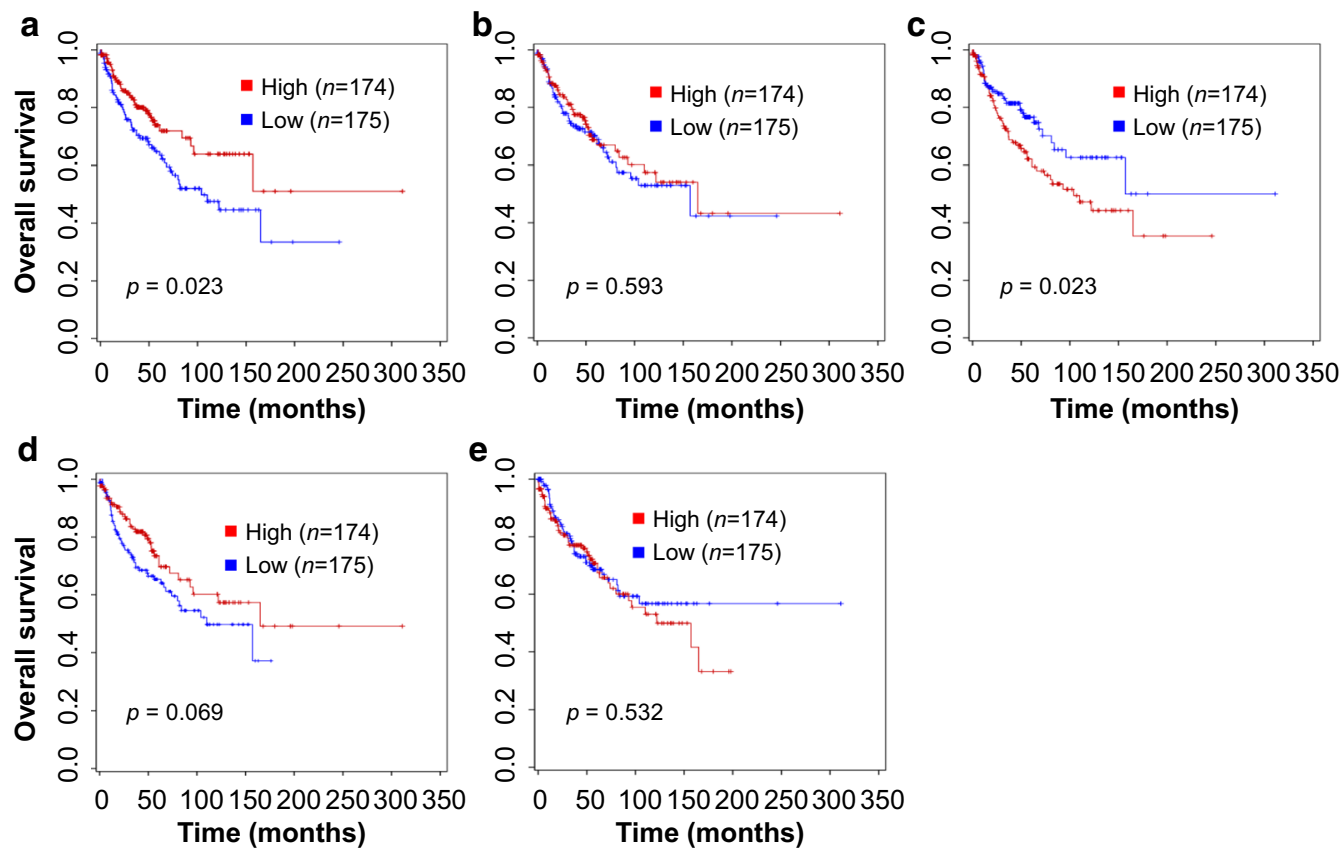

Fig. 3 The Kaplan-Meier survival analysis of NSCLC patients. Patients expressing CD68 had better overall survival than patients who did not (OS rate, $78.2 \%$ vs. $68.6 \%$, log rank $p=0.023)(\mathbf{a})$, while CD163 was not associated with patient survival (b). Patients with a high M2 ratio (CD163/CD68) had significantly shorter overall survival than patients with a low M2 ratio (OS rate, $68.4 \%$ vs. $78.3 \%$, log rank $p=0.023$ ) (c). There were no meaningful overall survival differences for VEGF-A (d) and VEGF-C (e) expression in NSCLC patients
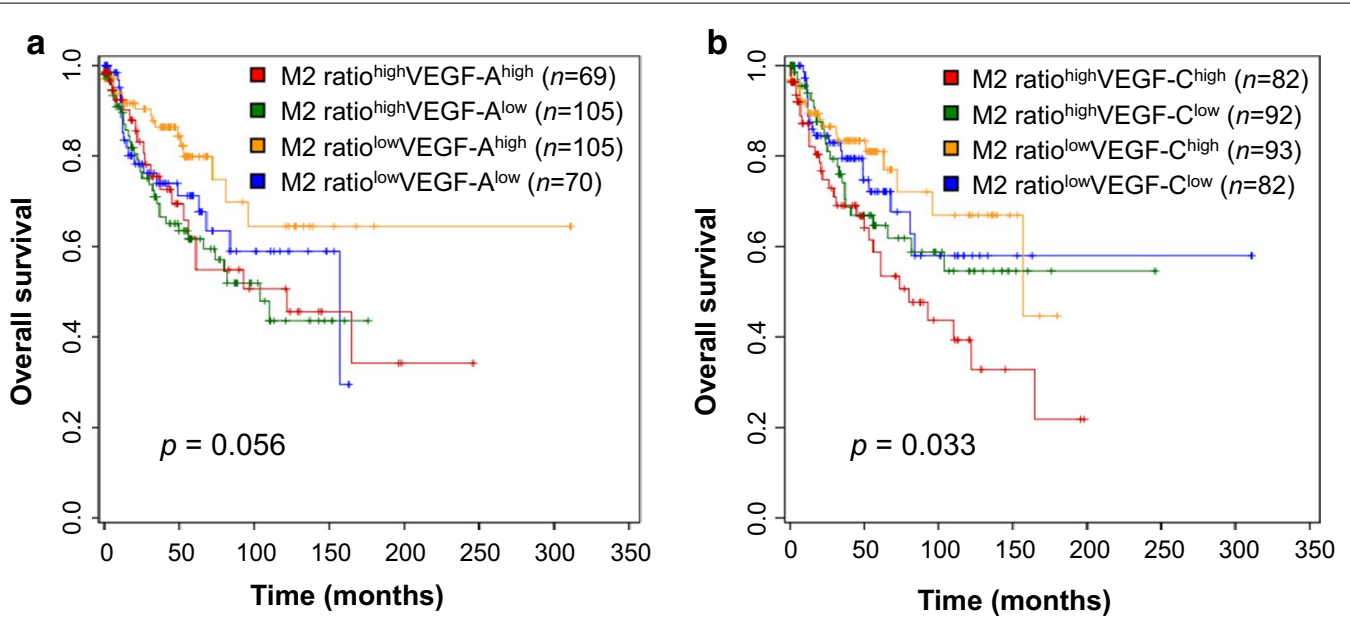

Fig. 4 Survival analysis of NSCLC patients with M2 ratio expression according to angiogenesis (VEGF-A) or lymphangiogenesis (VEGF-C) marker expression in NSCLC patients. Dual expression of high M2 ratio and high VEGF-A (M2 ratio ${ }^{\text {high/VEGF-A }}{ }^{\text {high }}$ ) exhibited a tendency of worse overall

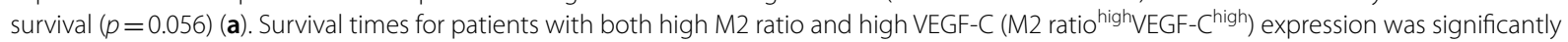

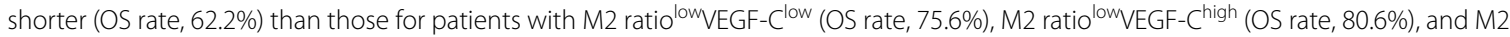
ratio ${ }^{\text {high } V E G F-C l o w ~}(O S$ rate, $73.9 \%)(\log$ rank $p=0.033)(\mathbf{b})$

ratio ${ }^{\text {high }}$ VEGF-C ${ }^{\text {low }}(\log$-rank $p=0.112)$ groups. Patients with M2 ratio ${ }^{\text {high }}$ VEGF-C $C^{\text {high }}$ had the worst overall survival compared to patients with M2 ratio ${ }^{\text {low }}$ VEGF-C $C^{\text {high }}$ (OS rate, $62.6 \% v s .80 .6 \%$, log-rank $p=0.033$, Fig. $4 \mathrm{~b}$ ).
In subgroup analyses, adenocarcinoma NSCLC patients with M2 ratio ${ }^{\text {high }}$ VEGF- $A^{\text {high }}$ had shorter survival time than those with M2 ratio ${ }^{\text {low }}$ VEGF-A ${ }^{\text {high }}$ (OS rate, $72.7 \%$ vs. $93.3 \%$, log-rank $p=0.027$ ) (Additional 
file 2: Fig. S6a). Similarly, the survival times of patients with M2 ratio ${ }^{\text {high }}$ VEGF-C ${ }^{\text {high }}$ were worse than those of patients with M2 ratio ${ }^{\text {low }}$ VEGF-C ${ }^{\text {high }}$ (OS rate, $69.2 \%$ vs. 91.5\%, log-rank $p=0.042$ ) (Additional file 2: Fig. S6b). In pairwise comparisons, significant survival difference was observed between groups with M2 ratio ${ }^{\text {high }}$ VEGF-A ${ }^{\text {high }}$ and M2 ratio ${ }^{\text {low }}$ VEGF-A $\mathrm{A}^{\text {high }}$ (pairwise comparison, $p=0.003)$. Similarly, there also significant difference of survival rate between groups M2 ratio ${ }^{\text {high }}$ VEGF-C ${ }^{\text {high }}$ and with M2 ratio ${ }^{\text {low }}$ VEGF-C ${ }^{\text {high }}$ (pairwise comparison, $p=0.004$ ) expression in adenocarcinomas. However, there were no significant survival differences for combined M2 ratio and VEGF-A or VEGF-C expression in squamous cell carcinomas (Additional file 2: Fig. S7).

\section{Univariate and multivariate analyses for overall survival}

Clinicopathological characteristics were associated with patient survival by univariate analysis (Table 2). High pT stage $(p<0.001)$, high $\mathrm{pN}$ stage $(p<0.001)$, high M2 ratio $(p=0.024)$, and dual M2 ratio ${ }^{\text {high }}$ and VEGF-C $C^{\text {high }}$ $(p=0.007)$ were associated with worse patient survival, while high CD68 expression correlated with good survival $(p=0.024)$. However, age, tumor grade, high CD163 expression, high VEGF-A expression, high VEGF-C expression, dual M2 ratio ${ }^{\text {high }}$ and VEGF-A high were not associated with patient survival. Furthermore, Cox multivariate proportional hazard analysis revealed that high pT stage (hazard ratio 2.91 [95\% CI 1.77-4.78], $p<0.001$ ), high pN stage (hazard ratio 2.02 [95\% CI 1.31-3.11], $p=0.002$ ), high M2 ratio (hazard ratio 1.53 [95\% CI $1.01-2.33$ ], $p=0.046)$, and dual M2 ratio ${ }^{\text {high }}$ and VEGF$\mathrm{C}^{\text {high }}$ expression (hazard ratio 2.01 [95\% CI 1.28-3.16], Table 2 Univariate analysis of the association
between prognostic variables and overall survival
in NSCLC

\begin{tabular}{|c|c|c|}
\hline Variables & Hazard ratio $(95 \% \mathrm{Cl})$ & $p$ value \\
\hline Age & $1.01(0.99-1.04)$ & 0.267 \\
\hline Tumor grade & $1.22(0.93-1.60)$ & 0.146 \\
\hline pT stage & $3.57(2.21-5.76)$ & $<0.001$ \\
\hline pN stage & $2.59(1.72-3.91)$ & $<0.001$ \\
\hline CD68 high & $0.62(0.41-0.94)$ & 0.024 \\
\hline CD163 high & $0.89(0.60-1.35)$ & 0.594 \\
\hline VEGF-A ${ }^{\text {high }}$ & $0.68(0.45-1.03)$ & 0.071 \\
\hline VEGF-Chigh & $1.14(0.76-1.71)$ & 0.531 \\
\hline M2 ratio ${ }^{\text {high }}$ & $1.61(1.07-2.44)$ & 0.024 \\
\hline Dual M2 ratio ${ }^{\text {high }} \&$ VEGF-A $A^{\text {high }}$ & $1.23(0.74-2.02)$ & 0.424 \\
\hline Dual M2 ratio ${ }^{\text {high }}$ \& VEGF-Chigh & $1.82(1.18-2.80)$ & 0.007 \\
\hline
\end{tabular}

M2 ratio, CD163+/CD68+

NSCLC non-small cell lung cancer, $C l$ confidence interval, VEGF vascular endothelial growth factor $p=0.003)$ are independent prognosis factors for poor overall survival in NSCLC patients (Table 3 ).

\section{Effect of macrophage polarization on angiogenesis and lymphangiogenesis}

In order to investigate the effect of M1 and M2 macrophages on VEGF-A and VEGF-C expression in NSCLC, macrophages polarized toward M1 type (pro-inflammatory) or M2 type (anti-inflammatory) were co-cultured with A549 cells, a human NSCLC cell line. Human monocytic THP-1 cells were differentiated into macrophages (unpolarized M0 macrophages) by PMA treatment for $24 \mathrm{~h}$, and these macrophages were seeded into transwell inserts. M0 THP-1 macrophages were polarized toward M1 type by $24 \mathrm{~h}$ incubation with LPS $(10 \mathrm{ng} / \mathrm{ml})$, or M2 type with recombinant human IL4+ IL13 (each of $20 \mathrm{ng}$ / $\mathrm{ml}$ ) in transwell inserts. Polarized M1, M2, and unpolarized M0 macrophages were washed 3 times with PBS, and co-cultured with A549 cells. VEGF-A and VEGF-C protein levels in cell lysate were assessed by ELISA, and mRNA levels in THP-1 macrophages and A549 cells at the time of co-culture were measured by quantitative real-time PCR. As shown in Fig. $5 a-d$, there were no significant changes in mRNA and protein expression of VEGF-A and VEGF-C in A549 cells co-cultured with M0 macrophages. A549 cells co-cultured with M2 macrophages exhibited significantly elevated VEGF-A and VEGF-C protein and mRNA levels $(p<0.001)$ compared to those of A549 cells alone. M1 macrophages induced mRNA expression of $V E G F-A$ significantly in A549 cells $(p=0.004)$, but did not affect VEGF-A protein levels. Interestingly, M1 macrophages did not affect VEGF-C protein and mRNA expression in A549 cells. Co-culturing with $\mathrm{M} 2$ macrophages drastically increased the levels of VEGF-A and VEGF-C mRNA in A549 cells, compared to co-culturing with $\mathrm{M} 1$ macrophages. The protein and mRNA expression levels of both molecules were assessed in THP-1 macrophages (Fig. 5e-h) as well. VEGF-A

\begin{tabular}{|c|c|c|c|c|}
\hline Variables & Hazard ratio $(95 \% \mathrm{Cl})$ & Se (Coef) & $z$ & $p$ value \\
\hline pT stage & $2.91(1.77-4.78)$ & 0.254 & 4.196 & $<0.001$ \\
\hline pN stage & $2.02(1.31-3.11)$ & 0.221 & 3.171 & 0.002 \\
\hline M2 ratio ${ }^{\text {high }}$ & $1.53(1.01-2.33)$ & 0.214 & 1.992 & 0.046 \\
\hline $\begin{array}{l}\text { Dual M2 } \\
\text { ratio high \& } \\
\text { VEGF-Chigh }\end{array}$ & $2.01(1.28-3.16)$ & 0.231 & 3.028 & 0.003 \\
\hline
\end{tabular}

$\mathrm{M} 2$ ratio, $\mathrm{CD} 163+/ \mathrm{CD} 68+$

NSCLC non-small cell lung cancer, $C l$ confidence interval, VEGF vascular endothelial growth factor 

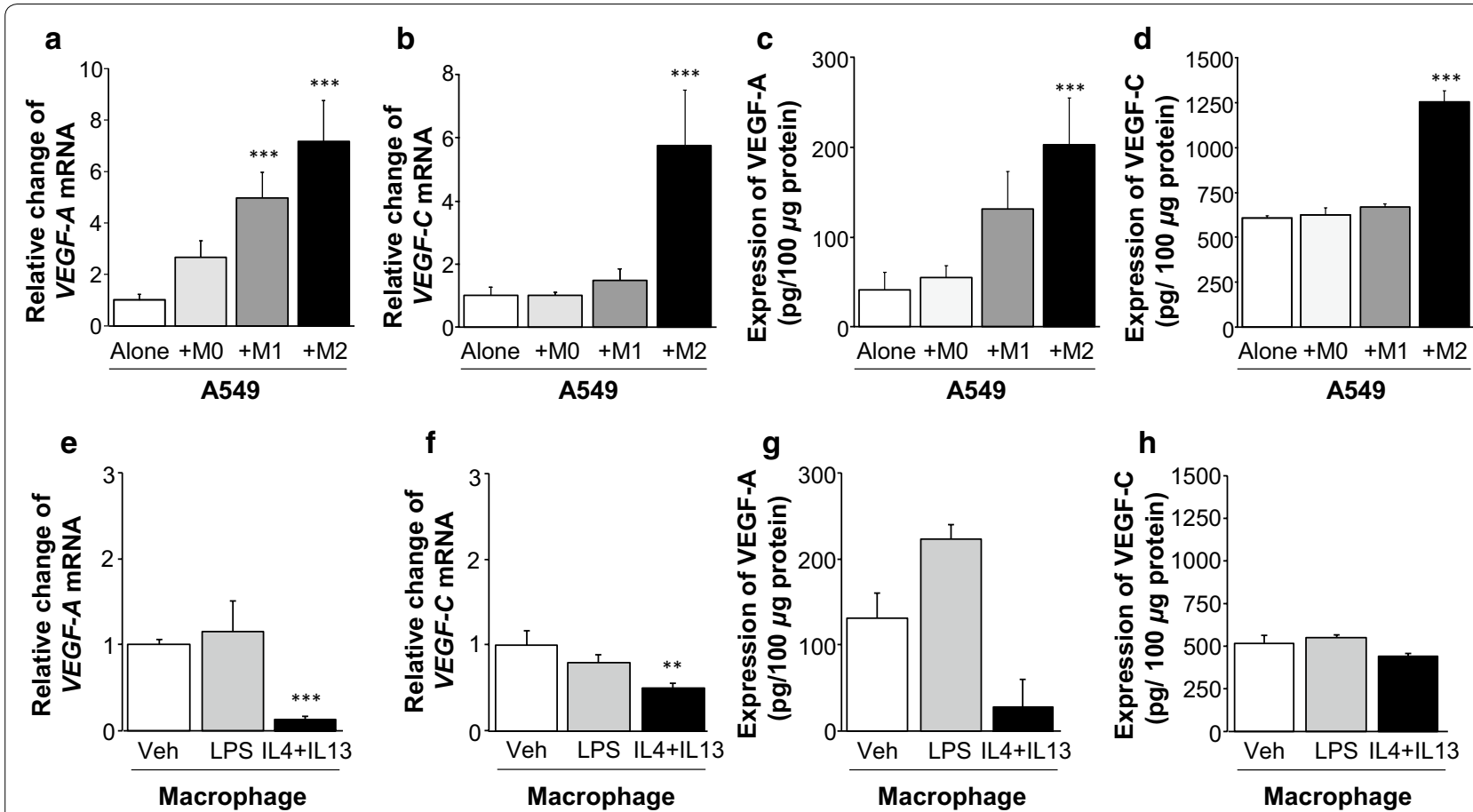

Fig. 5 Effect of macrophage polarization on NSCLC cell angiogenesis and lymphangiogenesis. A549 cells were co-cultured with M0 macrophages, M1 macrophages, polarized by LPS, or M2 macrophages, polarized by IL4 + IL 13. After $48 \mathrm{~h}$ of co-culture, total RNA and protein were extracted from the cells as indicated. Gene expression was assessed with quantitative real-time PCR $(\mathbf{a}, \mathbf{b})$, and protein expression was quantitated using specific ELISA kits (c, d). VEGF-A and VEGF-C mRNA levels increased in M2 macrophages significantly. However, M1 macrophages elevated only VEGF-A mRNA, not VEGF-C, in A549 cells. In order to assess the levels of VEGF-A and VEGF-C mRNA in polarized macrophages, the macrophages were collected after $72 \mathrm{~h}$ of culturing with LPS or IL $4+I \mathrm{~L} 13$, total RNA and proteins were extracted, and gene and protein expression were assessed with quantitative real-time PCR $(\mathbf{e}, \mathbf{f})$ and ELISA $(\mathbf{g}, \mathbf{h})$ as well. The mRNA levels of VEGF-A and VEGF-C were significantly decreased in M2 macrophages polarized by IL4 + IL13, compared to M1 macrophages polarized by LPS or M0 macrophages cultured with vehicles. Error bars represent S.D; ${ }^{*} p<0.05,{ }^{* *} p<0.01,{ }^{* * *} p<0.001$. Asterisk represents the significance compared to A549 alone or macrophage with vehicle

protein and mRNA expression did not significantly differ between M1 macrophages treated with LPS and unpolarized M0 unpolarized macrophages (with vehicle). Contrastingly, VEGF-C protein and mRNA levels were decreased in M2 macrophages treated with IL4+IL13 compared to M0, unpolarized macrophages.

\section{Discussion}

The management of advanced NSCLC has significantly improved in recent years with the advent of moleculartargeted therapies [27, 28]. Nonetheless, the prognosis of advanced NSCLC remains poor and the outcomes for NSCLC patients have improved finitely during the past decades. Recently, immunotherapies using immune checkpoint inhibitors have exhibited their superiority over chemotherapy, especially in advanced stage NSCLC patients [5, 29, 30]. However, only a limited number of patients achieved significant improvement in overall survival and progression-free survival amongst the unscreened and immunotherapy-treated patients. In addition, immunotherapy has limitations including many side effects and expensive treatment costs. It is especially important to find a reliable biomarker that can be used to precisely screen NSCLC patients for immunotherapy. In this study, we confirmed that patients with high M1 macrophage expression had significantly better overall survival compared to patients with low infiltration of M1 macrophages, while patients with high M2 ratio (CD163+/CD68+) had significantly worse overall survival compared to that of patients with low M2 ratio. Furthermore, we found a potential linkage between TAMs, angiogenesis and lymphangiogenesis. Notably, the combination of high M2 ratio and high VEGF-C expression was an independent prognostic factor for poor overall survival in NSCLC patients.

The TME, which consists of various cells and extracellular components, has been spotlighted for not only playing a pivotal role during tumor initiation, progression and metastasis, but also being highly associated with tumor relapse after conventional anticancer therapies. TAMs are key components of the TME and can have functionally distinct characteristics in response to environmental 
cues [31, 32]. They are categorized into two subsets: classically activated (M1) or alternately activated (M2). M1 macrophages inhibit tumor growth by producing reactive oxygen intermediates, reactive nitrogen intermediates, and tumor necrosis factor alpha (TNF $\alpha$ ), whereas M2 macrophages promote tumor growth and metastasis by secreting matrix-degrade enzymes, angiogenic factors and immunosuppressive cytokines/chemokines [33]. Thus, the quantitation of TAM expression can be an invaluable clinical indicator for managing patients with NSCLC. Ma et al. [34] and Rakaee et al. [35] have previously reported that a high density of M1 macrophages in tumor islets and tumor stroma is associated with favorable patient survival outcomes. Likewise, our study results showed that high CD68 expression in tumor stroma is associated with good prognosis. On the other hand, Cao et al. found no correlation between CD68 density in the tumor interstitial region and overall survival of NSCLC patients [36]. These controversial data may be explained by the unique characteristics of TAMs, which have dynamic and heterogenous phenotypes in response to the local TME. In addition, CD68 is a relatively nonspecific marker, necessitating the development of a specific marker for M1 macrophages. Similarly, reports on the prognostic value of M2 macrophages in NSCLC are inconsistent. CD163 is a specific marker for M2 macrophages and has been used for immunohistochemistry via single or ratio assessment (CD163/ CD68) [37]. Previous studies have shown that high levels of M2 macrophages in tumor islets and stroma are positively associated with negative outcomes in NSCLC patients, while others found no correlation between M2 macrophages and clinical outcomes of NSCLC patients [34]. Prior studies demonstrated that IHC interpreted via digital image analysis allows better predictions of prognostic relevance than manual visual scoring $[38,39]$. We have also previously confirmed that digital image analysis resulted in better clinical value than traditional manual scoring [40]. Moreover, we have also demonstrated that ratio-based biomarkers can provide enhanced prognostic value over assessment of individual biomarkers [41, 42]. This approach requires continuous quantitative values from digital image analysis. We found that TAMs were mostly distributed in the tumor stroma, which corroborates previous data [43]. Thus, we assessed TAM expression by combining immunohistochemistry and quantitative image analysis to study the tumor stroma. High M2 ratio (CD163+/CD68+) was associated with poor prognosis in NSCLC, but there was no meaningful clinical value from the M2 macrophage assessment using only CD163. Notably, high M2 ratio was an independent prognostic factor for poor overall survival in NSCLC patients. In contrast, Rakaee et al. reported that high M2 ratio (CD204+/CD68+) was an independent prognostic factor for good disease specific survival in NSCLC patients [35]. This inconsistency may partially be explained by the lack of a standard algorithm for TAMs, different IHC methodology, or differences in the studies' patient populations.

Previous studies suggested that the VEGF-A/vascular endothelial growth factor receptor-2 (VEGFR-2) axis is the major pathway for angiogenesis [44], while the VEGF-C/VEGF-D/ vascular endothelial growth factor receptor-3 (VEGFR-3) axis is involved in lymphangiogenesis of cancer [45]. VEGF-A is an endogenous agonist for VEGFR-2 and its signaling is targeted through neutralizing circulating VEGF-A using bevacizumab [46], or inhibiting downstream signaling pathways [47]. On the other hand, VEGF-C overexpression promotes nodal and distant organ metastasis [48], while VEGF-C knockdown inhibits these properties [49]. We previously demonstrated that SCP3 expression is closely associated with VEGF-C and VEGF-D expression, and potentially linked with lymphangiogenesis in NSCLC patients [40]. Given that VEGF-A and VEGF-C has been implicated in angiogenesis and lymphangiogenesis in cancer development, many studies have investigated the prognostic value of VEGF-A and VEGF-C in NSCLC patient tissues. However, the prognostic value of VEGF-A and VEGF-C is still controversial. VEGF-A has been reported to be associated with survival time $[50,51]$, but other reports conflict with these results $[52,53]$. A similar finding for the clinical value of VEGF-C in NSCLC has also been previously reported. VEGF-C has been shown to be linked with lymph node metastasis in NSCLC [54, 55]. Jiang et al., showed that VEGF-C expression is associated with poor prognosis for NSCLC patients, but not with clinical outcomes for patients with lung adenocarcinoma, via meta-analysis of 1988 patients aggregated from 16 trials [56]. In contrast, prior studies indicated there is no significant correlation between VEGF-C expression and lymph node metastasis in NSCLC. Interestingly, VEGF$C$ mRNA expression in patients with lymph node metastasis was lower compared to that of patients without metastasis [57]. Previous studies also reported that there is no correlation between VEGF-C expression and lymph node metastasis $[58,59]$. In this study, we also observed that there was no meaningful association between VEGFA and prognostic value in NSCLC. Similarly, VEGF-C expression did not correlate with lymph node metastasis. The complex environment of VEGFs and VEGFRs during NSCLC development might be one of the reasons for these inconsistent conclusions. In this study, we demonstrated that the analysis of macrophage subtypes could improve prognosis prediction for NSCLC patients. Moreover, we found that accumulation of M2 TAMs is 
positively associated with levels of VEGF-A and VEGF-C in NSCLC. Further studies are needed to define whether these combinational markers will help screen NSCLC patients for immunotherapy.

TAMs generally acquire a M2-like phenotype [43] to help promote tumor growth and metastasis $[60,61]$. It is thought that TAMs are regulated by an angiogenic switch, which is a critical step in the transition to malignancy. Lin et al. demonstrated that inhibition of macrophage infiltration in tumors delays the angiogenic switch and malignant transition in a mouse model of breast cancer [62]. This study suggests that the angiogenic switch does not occur in the absence of macrophages. Moreover, during the angiogenetic switch, macrophages promote blood vessel maturation and vascular permeability by VEGF secretion [63]. Recently, Alishekevitz et al. demonstrated that TAMs promote lymphangiogenesis via the VEGF-C/ VEGFR-3 pathway [64]. However, the detailed molecular mechanism behind the association of TAMs and angiogenesis or lymphangiogenesis is not fully understood. To understand the dynamics of polarized TAMs in the context of lymphangiogenesis via VEGF-A and -C in NSCLC, A549 cells were co-cultured with THP-1 macrophages polarized by LPS (for M1 type) or interleukin 4 (IL4)/ interleukin 13 (IL13) (for M2 type) treatment. Interestingly, VEGF-A and -C protein levels remained unchanged in M1 and M2 macrophages, while mRNA levels of both molecules were significantly decreased in M2 macrophages. However, M2 macrophages provoked a significant increase in VEGF-A and -C proteins and mRNA in A549 cells, while M1 macrophages only increased VEGF-A mRNA. These data suggest that accumulated M2 TAMs can stimulate the production of VEGF-A and $-C$, which promote angiogenesis and lymphangiogenesis. VEGF-A and -C mediated angiogenesis and lymphangiogenesis enhances the potential of NSCLC metastasis. Since the M2 macrophage and A549 co-cultures did not allow cell-cell interaction, secretory molecules from M2 macrophages were involved in this interaction. Therefore, further studies should be performed to find potential stimulatory molecules that are secreted to aid the production of VEGF-A and -C in NSCLC, and ultimately develop anticancer therapeutics to target this interaction.

\section{Conclusions}

CD68 and CD163 expression in tumor stroma were positively correlated with VEGF-A and VEGF-C in NSCLC patients' tissues. High M2 ratio (CD163+/CD68+) in the tumor stroma is a potential marker for predicting malignant clinical outcomes in NSCLC patients, and consideration of $\mathrm{M} 2$ ratio and VEGF-C expression in combination may enhance the accuracy of prognostic prediction. Furthermore, our findings suggest that increased M2 TAMs can promote VEGF-A and -C expression in NSCLC cells, which contribute to angiogenesis and lymphangiogenesis within the tumor site. Further studies are warranted to explore the detailed molecular mechanisms of the crosstalk between M2 macrophages and VEGFs in NSCLC.

\section{Supplementary information}

Supplementary information accompanies this paper at https://doi. org/10.1186/s12967-020-02618-z.

Additional file 1: Table S1. Clinicopathological characteristics of patients with NSCLC. Table S2. Association between clinicopathological factors and combination of M2 ratio and VEGF-A expression in NSCLC. Table S3. Association between clinicopathological factors and combination of $\mathrm{M} 2$ ratio and VEGF-C expression in NSCLC. Table S4. Association between clinicopathological parameters and CD68, CD163, VEGF-A, or VEGF-C expression as well as M2 ratio in NSCLC patients with squamous cell carcinomas. Table S5. Association between clinicopathological parameters and CD68, CD163, VEGF-A, or VEGF-C expression as well as M2 ratio in NSCLC patients with adenocarcinomas

Additional file 2: Fig. S1 Association between tumor-associated macrophage and VEGFs in human non-small cell lung cancer (NSCLC). Correlation between tumor-associated macrophage and VEGF-A (a) and VEGF-C (b). Fig. S2 Correlation among tumor-associated macrophage-, angiogenesis- and lymphangiogenesis-related markers in patients with adenocarcinoma NSCLC. CD68 expression positively correlated with CD163 (a), VEGFA (b), and VEGF-C (c) expression. CD163 expression showed a significant positive correlation with VEGF-A (d), but a weak correlation with VEGF-C (e) expression. There is a positive correlation between VEGF-A and VEGF-C (f). Fig. S3 Correlation among tumor-associated macrophage-, angiogenesis- and lymphangiogenesis-related markers in patients with squamous cell carcinoma NSCLC. CD68 expression positively correlated with CD163 (a), VEGF-A (b), and VEGF-C (c) expression. CD163 expression showed a moderate correlation with VEGF-A (d) and VEGF-C (e) expression. There is a significant positive correlation between VEGF-A and VEGF-C (f). Fig. S4 Kaplan-Meier survival curves for tumor-associated macrophage-, angiogenesis- and lymphangiogenesis-related markers in NSCLC patients with adenocarcinoma. Patients expressing CD68 had better overall survival than patients who did not (OS rate, $85.9 \%$ vs. $75.7 \%$, log rank $p=0.034$ ) (a), while CD163 was not associated with patient survival $(p=0.470)(\mathbf{b})$. Patients with a high M2 ratio (CD163/CD68) had significantly shorter overall survival than patients with a low M2 ratio (OS rate, $76.0 \%$ vs. $84.5 \%$, log rank $p=0.047)(\mathbf{c})$. There were no meaningful overall survival differences for VEGF-A ( $p=0.092)$ (d) and VEGF-C ( $p=0.899)$ (e) expression in NSCLC patients. Fig. S5 Kaplan-Meier survival curves for tumor-associated macrophage-, angiogenesis- and lymphangiogenesis-related markers in NSCLC patients with squamous cell carcinoma. There were no meaningful overall survival differences for CD $68(p=0.153)(\mathbf{a}), \operatorname{CD} 163(p=0.449)$ (b), M2 ratio $(p=0.682)(\mathbf{c}), \operatorname{VEGF-A}(p=0.091)(\mathbf{d})$ and VEGF-C $(p=0.670)$ (e) expression in NSCLC patients with squamous cell carcinoma. Fig. $\mathbf{S 6}$ Survival analysis of NSCLC patients with M2 ratio expression according to angiogenesis (VEGF-A) or lymphangiogenesis (VEGF-C) marker expression in NSCLC patients with adenocarcinoma. Survival differences were observed among 4 NSCLC patient groups classified according to their M2 ratio and VEGF-A expression (log rank $p=0.027$ ) (a). A significant difference of survival rate was found among 4 NSCLC patient groups classified according to their $\mathrm{M} 2$ ratio and VEGF-C expression (log rank $p=0.042$ ) (b). Fig. S7 Survival analysis of NSCLC patients with M2 ratio expression according to angiogenesis (VEGF-A) or lymphangiogenesis (VEGF-C) marker expression in NSCLC patients with squamous cell carcinoma. There were no meaningful overall survival differences for combination $\mathrm{M} 2$ ratio and VEGF-A ( $p=0.387)(\mathbf{a})$ or VEGF-C $(p=0.551)(\mathbf{b})$.

\section{Abbreviations}

TME: Tumor microenvironment; TAM: Tumor associated macrophage; NSCLC: Non-small cell lung cancer; TNM: Tumor, node, metastasis; IASLC: International 
Association for the Study of Lung Cancer; AJCC: American Joint Committee on Cancer; PD-L1: Programmed death ligand 1; TMB:Tumor mutation burden; TIL:Tumor-infiltrating lymphocytes; MSI: Microsatellite instability; VEGF: Vascular endothelial growth factor; WHO: World Health Organization; TMA: Tissue microarray; FFPE: Formalin-fixed, paraffin-embedded; H\&E: Hematoxylin and eosin; DAB: 3-3'-Diaminobenzidine; HRP: Horseradish peroxidase; AP: Alkaline phosphatase; DIA: Digital image analysis; PMA: Phorbol 12-myristate 13-acetate; LPS: Lipopolysaccharide; PCR: Polymerase chain reaction; ELISA: Enzyme-linked immunosorbent assay; HR: Hazard ratio; Cl: Confidence interval; TNFa: Tumor necrosis factor alpha; VEGFR-2: Vascular endothelial growth factor receptor-2; VEGFR-3: Vascular endothelial growth factor receptor-3; IL4: Interleukin 4; IL13: Interleukin 13.

\section{Acknowledgements}

We thank Dr. Cara Monroe for critical reading and comments.

\section{Authors' contributions}

JYC, and SMH conceived the study and devised the experimental design. $I \mathrm{H}$ KY, EJC, CP, and JYC performed experiments. IH, JWK, EJC, HK, JH, JF, JYC, and SMH performed data analysis for experiments and clinical records. $I H$, JWK, EJC, and JYC wrote the manuscript in consultation with SMH. All authors read and approved the final manuscript.

\section{Funding}

This research was supported in part by the Intramural Research Program of the National Institutes of Health, National Cancer Institute, Center for Cancer Research and a 2017 research promoting grant from the Keimyung University Dongsan Medical Center.

\section{Availability of data and materials}

The datasets used and/or analyzed for the current study are available upon reasonable request to the corresponding author.

\section{Ethics approval and consent to participate}

This study was reviewed and approved by the Institutional Review Board at Keimyung University Dongsan Medical Center (DSMC 2020-01-020, Daegu, Republic of Korea), Toyama University Hospital (Toyama, Japan), and National Hospital Organization Higashi-Ohmi General Medical Center (Shiga, Japan) and informed consent was obtained from each patient. All procedures were conducted in accordance with the Declaration of Helsinki.

\section{Consent for publication}

Not applicable.

\section{Competing interests}

The authors declare that there are no conflicts of interest.

\section{Author details}

${ }^{1}$ Experimental Pathology Laboratory, Laboratory of Pathology, Center for Cancer Research, National Cancer Institute, National Institutes of Health, MSC1500, Bethesda, MD 20892, USA. ${ }^{2}$ Radiation Oncology Branch, Center for Cancer Research, National Cancer Institute, National Institutes of Health, Bethesda, MD 20892, USA. ${ }^{3}$ Department of Thoracic Surgery, Vories Memorial Hospital, Shiga 523-0806, Japan. ${ }^{4}$ Advanced Biomedical Computational Science, Biomedical Informatics and Data Science, Leidos Biomedical Research, Inc., Frederick, MD 21702, USA. ${ }^{5}$ Department of Thoracic Surgery, Shiga University of Medical Science, Otsu 520-2192, Japan. ${ }^{6}$ Department of Pathology, Nagasaki University Graduate School of Biomedical Sciences, Nagasaki 852-8523, Japan. ${ }^{7}$ Department of Pathology, Keimyung University Scholl of Medicine and Institute for Cancer Research, Dongsan Medical Center, Daegu 42601 , Republic of Korea. ${ }^{8}$ Department of Pathology, Kangnam Sacred Heart Hospital, Hallym University College of Medicine, Seoul 07441, Republic of Korea.

Received: 5 September 2020 Accepted: 11 November 2020 Published online: 23 November 2020

\section{References}

1. Siegel RL, Miller KD, Jemal A. Cancer statistics, 2018. CA Cancer J Clin. 2018;68:7-30.
2. Facchinetti F, Bluthgen MV, Tergemina-Clain G, Faivre L, Pignon JP, Planchard D, Remon J, Soria JC, Lacroix L, Besse B. LKB1/STK1 1 mutations in non-small cell lung cancer patients: descriptive analysis and prognostic value. Lung Cancer. 2017;112:62-8.

3. Herbst RS, Heymach JV, Lippman SM. Lung cancer. N Engl J Med. 2008;359:1367-80.

4. Herbst RS, Baas P, Kim DW, Felip E, Perez-Gracia JL, Han JY, Molina J, Kim JH, Arvis CD, Ahn MJ, et al. Pembrolizumab versus docetaxel for previously treated, PD-L1-positive, advanced non-small-cell lung cancer (KEYNOTE-010): a randomised controlled trial. Lancet. 2016;387:1540-50.

5. Reck M, Rodriguez-Abreu D, Robinson AG, Hui R, Csoszi T, Fulop A, Gottfried M, Peled N, Tafreshi A, Cuffe S, et al. Pembrolizumab versus chemotherapy for PD-L1-positive non-small-cell lung cancer. N Engl J Med. 2016;375:1823-33.

6. Rizvi NA, Hellmann MD, Snyder A, Kvistborg P, Makarov V, Havel JJ, Lee W, Yuan J, Wong P, Ho TS, et al. Cancer immunology. Mutational landscape determines sensitivity to PD-1 blockade in non-small cell lung cancer. Science 2015:348:124-8.

7. Hellmann MD, Ciuleanu TE, Pluzanski A, Lee JS, Otterson GA, AudigierValette C, Minenza E, Linardou H, Burgers S, Salman P, et al. Nivolumab plus Ipilimumab in lung cancer with a high tumor mutational burden. N Engl J Med. 2018;378:2093-104.

8. Fridman WH, Zitvogel L, Sautes-Fridman C, Kroemer G. The immune contexture in cancer prognosis and treatment. Nat Rev Clin Oncol. 2017:14:717-34.

9. Boyiadzis MM, Kirkwood JM, Marshall JL, Pritchard CC, Azad NS, Gulley J. Significance and implications of FDA approval of pembrolizumab for biomarker-defined disease. J Immunother Cancer. 2018;6:35.

10. Li HY, McSharry M, Bullock B, Nguyen TT, Kwak J, Poczobutt JM, Sippel TR, Heasley LE, Weiser-Evans MC, Clambey ET, Nemenoff RA. The tumor microenvironment regulates sensitivity of murine lung tumors to PD-1/ PD-L1 antibody blockade. Cancer Immunol Res. 2017;5:767-77.

11. Vetizou M, Pitt JM, Daillere R, Lepage P, Waldschmitt N, Flament C, Rusakiewicz S, Routy B, Roberti MP, Duong CP, et al. Anticancer immunotherapy by $C T L A-4$ blockade relies on the gut microbiota. Science. 2015:350:1079-84.

12. Sinha P, Clements VK, Ostrand-Rosenberg S. Reduction of myeloidderived suppressor cells and induction of M1 macrophages facilitate the rejection of established metastatic disease. J Immunol. 2005;174:636-45.

13. Mantovani A, Allavena P, Sica A, Balkwill F. Cancer-related inflammation. Nature. 2008;454:436-44.

14. Mantovani A, Schioppa T, Porta C, Allavena P, Sica A. Role of tumor-associated macrophages in tumor progression and invasion. Cancer Metastasis Rev. 2006:25:315-22

15. Welsh TJ, Green RH, Richardson D, Waller DA, O'Byrne KJ, Bradding P. Macrophage and mast-cell invasion of tumor cell islets confers a marked survival advantage in non-small-cell lung cancer. J Clin Oncol. 2005;23:8959-67.

16. da Costa SP, Parra ER, Atanazio MJ, da Silva OB, Noleto GS, Ab'Saber AM, de Morais FS, Takagaki T, Capelozzi VL. Different morphology, stage and treatment affect immune cell infiltration and long-term outcome in patients with non-small-cell lung carcinoma. Histopathology. 2012:61:587-96.

17. Stacker SA, Williams SP, Karnezis T, Shayan R, Fox SB, Achen MG. Lymphangiogenesis and lymphatic vessel remodelling in cancer. Nat Rev Cancer. 2014;14:159-72

18. Bailey C, Negus R, Morris A, Ziprin P, Goldin R, Allavena P, Peck D, Darzi A Chemokine expression is associated with the accumulation of tumour associated macrophages (TAMs) and progression in human colorectal cancer. Clin Exp Metastasis. 2007;24:121-30.

19. Ikushima H, Miyazono K. TGFbeta signalling: a complex web in cancer progression. Nat Rev Cancer. 2010;10:415-24.

20. Waite KA, Eng C. From developmental disorder to heritable cancer: it's all in the BMP/TGF-beta family. Nat Rev Genet. 2003:4:763-73.

21. El-Chemaly S, Levine SJ, Moss J. Lymphatics in lung disease. Ann N Y Acad Sci. 2008;1131:195-202.

22. Ran S, Montgomery KE. Macrophage-mediated lymphangiogenesis: the emerging role of macrophages as lymphatic endothelial progenitors. Cancers (Basel). 2012;4:618-57. 
23. Otrock ZK, Makarem JA, Shamseddine Al. Vascular endothelial growth factor family of ligands and receptors: review. Blood Cells Mol Dis. 2007;38:258-68.

24. Chung JY, Kitano H, Takikita M, Cho H, Noh KH, Kim TW, Ylaya K, Hanaoka J, Fukuoka J, Hewitt SM. Synaptonemal complex protein 3 as a novel prognostic marker in early stage non-small cell lung cancer. Hum Pathol. 2013;44:472-9.

25. Detterbeck FC, Boffa DJ, Kim AW, Tanoue LT. The eighth edition lung cancer stage classification. Chest. 2017:151:193-203.

26. Kim JW, Jun SY, Ylaya K, Chang HK, Oh YH, Hong SM, Chung JY, Hewitt SM. Loss of HES-1 expression of predicts a poor prognosis for small intestinal adenocarcinoma patients. Front Oncol. 2020;10:1427.

27. Mok TS, Wu YL, Thongprasert S, Yang CH, Chu DT, Saijo N, Sunpaweravong P, Han B, Margono B, Ichinose Y, et al. Gefitinib or carboplatin-paclitaxel in pulmonary adenocarcinoma. N Engl J Med. 2009;361:947-57.

28. Zhou C, Wu YL, Chen G, Feng J, Liu XQ, Wang C, Zhang S, Wang J, Zhou $S$, Ren $S$, et al. Erlotinib versus chemotherapy as first-line treatment for patients with advanced EGFR mutation-positive non-small-cell lung cancer (OPTIMAL, CTONG-0802): a multicentre, open-label, randomised, phase 3 study. Lancet Oncol. 2011;12:735-42.

29. Brahmer J, Reckamp KL, Baas P, Crino L, Eberhardt WE, Poddubskaya E, Antonia S, Pluzanski A, Vokes EE, Holgado E, et al. Nivolumab versus docetaxel in advanced squamous-cell non-small-cell lung cancer. N Engl J Med. 2015;373:123-35.

30. Borghaei H, Paz-Ares L, Horn L, Spigel DR, Steins M, Ready NE, Chow $L Q$, Vokes EE, Felip E, Holgado E, et al. Nivolumab versus docetaxel in advanced nonsquamous non-small-cell lung cancer. N Engl J Med. 2015;373:1627-39.

31. Jackute J, Zemaitis M, Pranys D, Sitkauskiene B, Miliauskas S, Vaitkiene S, Sakalauskas R. Distribution of M1 and M2 macrophages in tumor islets and stroma in relation to prognosis of non-small cell lung cancer. BMC Immunol. 2018;19:3.

32. van Dalen FJ, van Stevendaal M, Fennemann FL, Verdoes M, Ilina O. Molecular repolarisation of tumour-associated macrophages. Molecules. 2018;24:65.

33. Mantovani A, Sica A, Locati M. Macrophage polarization comes of age. Immunity. 2005;23:344-6.

34. Ma J, Liu L, Che G, Yu N, Dai F, You Z. The M1 form of tumor-associated macrophages in non-small cell lung cancer is positively associated with survival time. BMC Cancer. 2010;10:112.

35. Rakaee M, Busund LR, Jamaly S, Paulsen EE, Richardsen E, Andersen S, Al-Saad S, Bremnes RM, Donnem T, Kilvaer TK. Prognostic Value of Macrophage Phenotypes in Resectable Non-Small Cell Lung Cancer Assessed by Multiplex Immunohistochemistry. Neoplasia. 2019;21:282-93.

36. Cao L, Che X, Qiu X, Li Z, Yang B, Wang S, Hou K, Fan Y, Qu X, Liu Y. M2 macrophage infiltration into tumor islets leads to poor prognosis in non-small-cell lung cancer. Cancer Manag Res. 2019;11:6125-38.

37. Yang C, Wei C, Wang S, Shi D, Zhang C, Lin X, Dou R, Xiong B. Elevated CD163(+)/CD68(+) ratio at tumor invasive front is closely associated with aggressive phenotype and poor prognosis in colorectal cancer. Int J Biol Sci. 2019;15:984-98.

38. Camp RL, Dolled-Filhart M, King BL, Rimm DL. Quantitative analysis of breast cancer tissue microarrays shows that both high and normal levels of HER2 expression are associated with poor outcome. Cancer Res. 2003;63:1445-8.

39. Harigopal M, Barlow WE, Tedeschi G, Porter PL, Yeh IT, Haskell C, Livingston R, Hortobagyi GN, Sledge G, Shapiro C, et al. Multiplexed assessment of the southwest oncology group-directed intergroup breast cancer trial $\$ 9313$ by AQUA shows that both high and low levels of HER2 are associated with poor outcome. Am J Pathol. 2010;176:1639-47.

40. Kitano H, Chung JY, Noh KH, Lee YH, Kim TW, Lee SH, Eo SH, Cho HJ, Choi $\mathrm{CH}$, Inoue $\mathrm{S}$, et al. Synaptonemal complex protein 3 is associated with lymphangiogenesis in non-small cell lung cancer patients with lymph node metastasis. J Transl Med. 2017;15:138.

41. Chung JY, Hong SM, Choi BY, Cho H, Yu E, Hewitt SM. The expression of phospho-AKT, phospho-mTOR, and PTEN in extrahepatic cholangiocarcinoma. Clin Cancer Res. 2009;15:660-7.
42. Kitano H, Chung JY, Ylaya K, Conway C, Takikita M, Fukuoka J, Doki Y, Hanaoka J, Hewitt SM. Profiling of phospho-AKT, phospho-mTOR, phospho-MAPK and EGFR in non-small cell lung cancer. J Histochem Cytochem. 2014;62:335-46.

43. Sumitomo R, Hirai T, Fujita M, Murakami H, Otake Y, Huang CL. M2 tumor-associated macrophages promote tumor progression in nonsmall-cell lung cancer. Exp Ther Med. 2019;18:4490-8.

44. Hamerlik P, Lathia JD, Rasmussen R, Wu Q, Bartkova J, Lee M, Moudry P, Bartek J Jr, Fischer W, Lukas J, et al. Autocrine VEGF-VEGFR2-Neuropilin-1 signaling promotes glioma stem-like cell viability and tumor growth. J Exp Med. 2012;209:507-20.

45. Stacker SA, Achen MG, Jussila L, Baldwin ME, Alitalo K. Lymphangiogenesis and cancer metastasis. Nat Rev Cancer. 2002;2:573-83.

46. Guyot M, Hilmi C, Ambrosetti D, Merlano M, Lo Nigro C, Durivault J, Grepin R, Pages G. Targeting the pro-angiogenic forms of VEGF or inhibiting their expression as anti-cancer strategies. Oncotarget. 2017:8:9174-88.

47. Comunanza V, Bussolino F. Therapy for cancer: strategy of combining anti-angiogenic and target therapies. Front Cell Dev Biol. 2017;5:101.

48. Mandriota SJ, Jussila L, Jeltsch M, Compagni A, Baetens D, Prevo R, Banerji S, Huarte J, Montesano R, Jackson DG, et al. Vascular endothelial growth factor-C-mediated lymphangiogenesis promotes tumour metastasis. EMBO J. 2001;20:672-82.

49. Chen Z, Varney ML, Backora MW, Cowan K, Solheim JC, Talmadge JE, Singh RK. Down-regulation of vascular endothelial cell growth factor-C expression using small interfering RNA vectors in mammary tumors inhibits tumor lymphangiogenesis and spontaneous metastasis and enhances survival. Cancer Res. 2005;65:9004-11.

50. Fontanini G, Vignati S, Boldrini L, Chine S, Silvestri V, Lucchi M, Mussi A, Angeletti CA, Bevilacqua G. Vascular endothelial growth factor is associated with neovascularization and influences progression of nonsmall cell lung carcinoma. Clin Cancer Res. 1997;3:861-5.

51. Iwasaki A, Kuwahara M, Yoshinaga Y, Shirakusa T. Basic fibroblast growth factor (bFGF) and vascular endothelial growth factor (VEGF) levels, as prognostic indicators in NSCLC. Eur J Cardiothorac Surg. 2004;25:443-8.

52. Bonnesen B, Pappot H, Holmstav J, Skov BG. Vascular endothelial growth factor A and vascular endothelial growth factor receptor 2 expression in non-small cell lung cancer patients: relation to prognosis. Lung Cancer. 2009;66:314-8.

53. Liu J, Liu Y, Gong W, Kong X, Wang C, Wang S, Liu A. Prognostic value of insulin-like growth factor 2 mRNA-binding protein 3 and vascular endothelial growth factor-A in patients with primary non-small-cell lung cancer. Oncol Lett. 2019;18:4744-52.

54. Issa A, Le TX, Shoushtari AN, Shields JD, Swartz MA. Vascular endothelial growth factor- $\mathrm{C}$ and $\mathrm{C}-\mathrm{C}$ chemokine receptor 7 in tumor cell-lymphatic cross-talk promote invasive phenotype. Cancer Res. 2009;69:349-57.

55. Bi MM, Shang B, Wang Z, Chen G. Expression of CXCR4 and VEGF-C is correlated with lymph node metastasis in non-small cell lung cancer. Thorac Cancer. 2017;8:634-41.

56. Jiang $\mathrm{H}$, Shao W, Zhao W. VEGF-C in non-small cell lung cancer: metaanalysis. Clin Chim Acta. 2014:427:94-9.

57. Takizawa H, Kondo K, Fujino H, Kenzaki K, Miyoshi T, Sakiyama S, Tangoku A. The balance of VEGF-C and VEGFR-3 mRNA is a predictor of lymph node metastasis in non-small cell lung cancer. Br J Cancer. 2006:95:75-9.

58. Arinaga M, Noguchi T, Takeno S, Chujo M, Miura T, Uchida Y. Clinical significance of vascular endothelial growth factor $C$ and vascular endothelial growth factor receptor 3 in patients with nonsmall cell lung carcinoma. Cancer. 2003;97:457-64.

59. Ogawa E, Takenaka K, Yanagihara K, Kurozumi M, Manabe T, Wada H, Tanaka F. Clinical significance of VEGF-C status in tumour cells and stromal macrophages in non-small cell lung cancer patients. Br J Cancer. 2004;91:498-503.

60. Chung ES, Chauhan SK, Jin Y, Nakao S, Hafezi-Moghadam A, van Rooijen N, Zhang Q, Chen L, Dana R. Contribution of macrophages to angiogenesis induced by vascular endothelial growth factor receptor3-specific ligands. Am J Pathol. 2009;175:1984-92.

61. Kim KE, Koh YJ, Jeon BH, Jang C, Han J, Kataru RP, Schwendener RA, Kim JM, Koh GY. Role of CD11b+ macrophages in intraperitoneal 
lipopolysaccharide-induced aberrant lymphangiogenesis and lymphatic function in the diaphragm. Am J Pathol. 2009;175:1733-45.

62. Lin EY, Li JF, Gnatovskiy L, Deng Y, Zhu L, Grzesik DA, Qian H, Xue XN, Pollard JW. Macrophages regulate the angiogenic switch in a mouse model of breast cancer. Cancer Res. 2006;66:11238-46.

63. Dalton HJ, Armaiz-Pena GN, Gonzalez-Villasana V, Lopez-Berestein G, BarEli M, Sood AK. Monocyte subpopulations in angiogenesis. Cancer Res. 2014;74:1287-93.

64. Alishekevitz D, Gingis-Velitski S, Kaidar-Person O, Gutter-Kapon L, Scherer SD, Raviv Z, Merquiol E, Ben-Nun Y, Miller V, Rachman-Tzemah C, et al.
Macrophage-induced lymphangiogenesis and metastasis following paclitaxel chemotherapy is regulated by VEGFR3. Cell Rep. 2016;17:1344-56.

\section{Publisher's Note}

Springer Nature remains neutral with regard to jurisdictional claims in published maps and institutional affiliations.
Ready to submit your research? Choose BMC and benefit from:

- fast, convenient online submission

- thorough peer review by experienced researchers in your field

- rapid publication on acceptance

- support for research data, including large and complex data types

- gold Open Access which fosters wider collaboration and increased citations

- maximum visibility for your research: over $100 \mathrm{M}$ website views per year

At BMC, research is always in progress.

Learn more biomedcentral.com/submissions 